\title{
Assessment of Social Sustainability in Construction Projects Using Social Network
} Analysis

\author{
${ }^{1}$ Essam Almahmoud, ${ }^{2}$ Hemanta Kumar Doloi \\ ${ }^{1,2}$ Faculty of Architecture, Building and Planning, The University of Melbourne, Melbourne, Australia
}

\begin{tabular}{|c|c|}
\hline & ABSTRACT \\
\hline 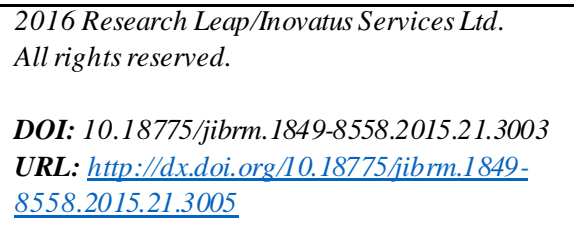 & $\begin{array}{l}\text { This paperaims to propose a framework that puts the stakeholders at the forefront of achieving } \\
\text { sustainability in the social context. This research, thus, argues that the social sustainability } \\
\text { outcomes in construction are best achieved by taking into account the satisfactions of the } \\
\text { stakeholders. Based on sustainability and equity theories, a dynamic assessment model has been } \\
\text { developed to evaluate the contributions of projects in a social context. Multiple stakeholders and } \\
\text { their differing interests associated with the construction projects have been integrated using }\end{array}$ \\
\hline $\begin{array}{l}\text { Keywords: } \\
\text { Urban planning, Sustainable development, Social } \\
\text { inclusion, Stakeholders, Stakeholder analysis, } \\
\text { Sustainability, Social environment }\end{array}$ & $\begin{array}{l}\text { respect to their relative stakes and seven social core functions, have been integrated in the } \\
\text { assessment model. The findings of this research suggest that the degree of satisfying the needs of } \\
\text { diverse stakeholders is highly significant in achieving social sustainability performance of } \\
\text { projects. Using a case study from Saudi Arabia, the applicability and significance of the } \\
\text { assessment model has been demonstrated. The application of the model provides the opportunity } \\
\text { to identify any problems and to enhance the overall performance ofprojects in the social context. } \\
\text { The functionality and efficacy of the model need to be further tested outside the Saudi Arabian } \\
\text { region. The research is original in the sense that for the first time, a novel approach has been } \\
\text { developed, putting the stakeholders at the forefront of achieving sustainability outcomes in } \\
\text { construction projects. }\end{array}$ \\
\hline
\end{tabular}

\section{Introduction}

The concept of sustainable development is premised on systems theory, which stipulates that the triple bottom line (TBL), i.e. the social, the economic and the environmental dimensions are interrelated; thus, each dimension needs to function properly to ensure the maintenance of the larger system(Dillard and King, 2008). The International Union for Conservation (IUCN, 1991) defined sustainable development as the improvement of the quality of human life within the carrying capacity of supporting ecosystems. Unfortunately, the first part of the definition has fallen off the agenda with the assumption that each development is an improvement in the quality of human life. Consequently, the social dimension has received less appreciation within the context of sustainable development (Hill and Bowen, 1997; Edum-Fotwe and Price, 2009). Therefore, there is an increased realisation of the need to develop new sustainability as ses sment tools that address all the TBL dimensions, especially the social dimension (Lützkendorf and Lorenz, 2006; Zhenhong et al., 2006; Edum-Fotwe and Price, 2009).

However, unlike the other sustainability dimensions, the nature of the social dimension includes greater portion of subjective attributes (Edum-Fotwe and Price, 2009). In particular, it has multi-faceted social values which, in turn, are influenced by numerous stakeholders. Although the aim of sustainable development is to meet the overall satisfaction of human needs, including the environmental, economic and social benefits, the priorities of human needs are hugely different. For instance, in Saudi Arabia, billions of dollars are spent in the construction industry; unfortunately, the money spent does not always guarantee many opportunities for jobs, skills development or improvements in the local economy (Allam, 2011). The end result has been the collapse of the apprenticeship system and, subsequently, a reduction in the national skills base, as well as the spread of inequity within the society.

Indeed, in the context of developing countries, Du Plessis (2002) and Talukhaba et al. (2005) highlighted the need for a significant shift of focus to the socio-economic issues rather than the environmental concerns in the development of modern projects. Hence, social needs and community perceptions should prevail over the project development decisions in terms of the traditional cost-benefit analysis or the six Green Star ratings. The social system in developing countries is evidently being ignored in project development, where issues such as 
inequity, health problems, poverty and illiteracy are of utmost importance in the value creation process.

Therefore, the integration of the stakeholders' interests in the assessment methodology has the potential to help the achievement of a balance between the development proposals and the meeting of the societal requirements. According to Clarkson (1995), the stakeholders interest-based approach is the best way to transfer the intangible issues (such as social performance) into tangible business objectives. Further, Van der Sluijs (2002) highlighted the need for a new generation of assessment models that could accommodate stakeholder value diversity, as well as interactions with them. In the light of the above, the current research aims to construct a framework encompassing the social issues as sociated with the nature of the construction projects and the relationships within the society. As asserted by Littig and Griessler (2005), social issues are created through the relationship between nature and society, and are mediated by work, as well as the relationship within the society. Further, according to Edum-Fotwe and Price (2009), the social issues within projects are created by the dynamic interaction of individuals' values within the community. Therefore, it can be stated that construction projects create new relationships and interactions within a community, as well as between a community and nature, which has the potential to contribute to meeting the needs and challenges within the society. Hence, the creation process of the social is sues, through the construction projects, needs to be carefully mapped to be aligned with the sustainable development objectives.

Although construction projects produce enormous social values, the complexity of the relationships of these values and the project stakeholders impede the measurement of the social performance. Therefore, a network view is fundamentally important in understanding the complex relations within the project development and operational environments (Pryke, 2012). Indeed, social network analysis (SNA) is becoming an increasingly popular methodology for understanding and mapping the complex patterns of the individual's interactions within a network system (Doloi, 2012; Pryke, 2012). Thus, using SNA as one of the key platforms, the current research puts forward a model enabling the measurement of the complex relations and, thereby, the quantification of the project's social production and effects. A case study from Saudi Arabia is used to demonstrate the usability and validity of the model.

\section{Background and Literature Review}

To establish the context of this research, a review of the available assessments and frameworks that relate to the concept of social sustainability is conducted and critiqued. The review highlighted the area to be improved and the need of the proposed framework. The need for stakeholders' consideration in the assessment is also highlighted to justify the research approach.

Over the past few decades, the field of Impact Assessments has been mostly dominated by traditional cost-benefit assessment and environmental impact assessment (EIA). EIA was developed in the early 1970s, and since then, it has received significant attention, especially after environmental issues emerged. The purpose of EIA is to systematically identify and evaluate the potential consequences of the impact of a project or a program on the environment (Rogers et al., 2008). The term environment and the is sues surrounding it have become a major dilemma across the world. In part, this has arisen, as it is being interpreted differently, so that it includes the social and economic aspects along with the ecological aspect, or the ecological aspect alone. Social impact assessment (SIA) was developed to help predict the social effects of the development or policy change on community alterations (Burdge, 1987) and to facilitate the identification and understanding of the consequences of the change to the human population and society; however, the use of the SIA in the planning process has been inconsistent (Burdge, 1987). Unfortunately, both impact assessment frameworks have failed to account for the positive outcomes and the meeting of the development goals (Vanclay, 2004).

In the context of a private project or company, social sustainability generally refers to corporate social responsibility (CSR). CSR usually denotes ethics and social responsibilities, along with the marketing benefits amongst the stakeholders which resulted from corporate activities with a social dimension (McGuire et al., 1988; Waddock and Graves, 1997). Maignan and Ferrell (2004) defined four primary viewpoints of CSR, including stakeholder obligations, social obligations, ethical commitment and managerial perspective.

Elkington (1998) asserted the term TBL to simply compel corporations to shift their focus towards the social and environmental dimensions along with their core interest on the economic dimension. Although the concept of TBL is being applied in development and operations of sustainable project, a clear consensus on the measure of the social dimensions leading to social sustainability is not quite prominent in the industry practice (Vanclay, 2004).

Moreover, Sustainable construction is a value-laden concept that emerges from multi-stakeholders perspectives including the whole supply chain (Liu et al., 2011). Therefore, the construction response to the CSR concept is fundamentally depended on the values held by the enterprises which will result on actions towards satisfying stakeholder demands (Green, 2009). Although construction projects are realised via a temporary multi-organisation, Liu et al. (2011) question the capability of CSR to be developed and have a meaningful application. Within this dynamic framework, the long-run and over-reaching objectives of CSR are difficult to be maintained. Therefore, the social performance in the construction industry is more appropriate to be realised in project context rather than following business paradigm of CSR.

Although many SIA guidelines and sustainability frameworks have been developed, including the Interorganisational Committee on Guidelines and Principles for SIA, the South Sydney Council SIA checklist, Vanclay's classifications of social impacts and the Dow Jones sustainability index, the scope of the social performance and the understanding of social impacts still remain obscure and lack robustness (Littig and Griessler, 2005; Missimer et al., 2010; Doloi, 2012). 
Missimer et al. (2010) have scrutinised the existing sustainability frameworks with respect to the social dimension and found that the social dimension lacks robustness, as well as not equally operational with the environmental and economic dimensions.

Previous sustainability assessment researches and their frameworks have been derived, mostly, from EIA or strategic environmental assessment. They were later extended to accommodate both the social and economic dimensions (Pope et al., 2004). However, although the assessments have the tendency to eliminate the negative impacts of a proposal, they fail to address sustainability as a societal goal.

Unlike economic and environmental indicators, at the micro level, social indicators are difficult to be identified, selected and measured (Vanclay, 2004; Edum-Fotwe and Price, 2009). The undefined socio-related factors and their subjectivity, as well as the different views and priorities of the stakeholders, make it difficult to identify what improvements are required (Bentivegna, 1997; Missimer et al., 2010). Additionally, different stakeholders have a variety of purposes for a project; hence, they expect different benefits and impacts, which need to be satisfied.This results in a range of understandings and evaluations of the reality of social sustainability performance (SSP; Pearce, 2006).

Bentivegna (1997) identified that the evaluation techniques are only able to represent some of the aspects of the whole system of effects, along with the sharing of only a few of the interests involved in the decision process. Further, Gibson (2006) noted that expertise, tools and techniques for sustainability evaluation are very helpful; however, they are unavoidably value-laden. Consequently, an important question arises as to whose value will take the dominant position. The answer is crucial, as the sustainable projects are concerned with equity. In other words, the response depends on which sustainability criteria are used, as well as how they are used. Vanclay (2004) raised the fundamental question of how social impacts should be weighted? Thus, the integration of the stakeholders' interests can show the way forward, but it is hugely difficult because of the stakeholders' diverse interests and perceptions.

Having identified the knowledge gap within the published research in the area of social sustainability, the current research aims to develop a dynamic model for social sustainability assessment. The output of the model is the quantified measurement of the project's ability to deliver social values to its stakeholders over the project's life cycle. More precisely, this research aims to answer the following key question:

How can the contribution of a construction project be evaluated with respect to its stakeholders in a social sustainability context?

To answer this question, the following objectives have been developed:

Identify the different communities of construction project's stakeholders.
- Define the social core functions (SCFs) of a construction project.

- $\quad$ Construct the social network between the stakeholders and their perceived interests in relation to the SCFs associated with the construction project.

- Develop a systematic evaluation framework of the SCFs over the project life cycle.

To develop an assessment model that takes into account the diverse stakeholders, the identification of the multiple stakeholders' communities associated with the construction projects is needed. Although different construction projects have different stakeholders, depending on their roles and responsibilities played in the project, they can be categorized in different community groups. Traditionally, the key stakeholders within construction projects are confined to owners, contractors and consultants. However, to evaluate the social performance of projects, the extended stakeholders and their short- and long-term needs and requirements are fundamentally an important consideration in any objective assessment. The second objective will then allow meeting the needs and requirements of the stakeholders across a few core functions in a social context. The third objective is then required to assess the conflicting (or diverse) needs and requirements of each stakeholder with respect to their relative stakes within the project. To assess these requirements of stakeholders, a methodical approach will need to be developed, incorporating the SCFs over the project life cycle which will be achieved through the fourth objective mentioned above.

To meet the above-mentioned research objectives, the research required a number of research methods. As a first step, a questionnaire survey was designed and distributed across the three broad stakeholders' communities (namely, industry, users and neighbourhood communities) in Saudi Arabian construction industry. As the attributes associated with the users and neighbourhood communities are specific to project contexts, the questionnaires for these two groups were confined to two case studies. However, as the attributes associated with the industry community is generic across most construction projects, a random survey approach was adopted for this community in the research. A total of 400 questionnaires were distributed across all three communities, of which, 250 valid responses were received. A sample of 62 per cent valid responses was considered highly relevant for deriving the SCFs adopted in the design of the as sess ment model. The results were analyzed using standard statistical methods, namely, standard deviation, mean and factor analysis (Field, 2009). Thus, the empirical derivation of the SCFs provides the significant measure of the social sustainability in the model. For investigating the social interactions between the stakeholders and the core functions in the assessment model, SNA was used (Pryke, 2012, p. 515).

For the sake of brevity, standard statistical methods have not been included in this paper, but will be presented in future papers. The focus of the remaining paper is on the development of the theoretical framework, the underlying mathematical 
models and the adaptation of the SCFs in the as ses sment model. The applicability and validity of the model is illustrated us ing a case study from Saudi Arabia.

\section{Theoretical framework}

The theoretical framework of this research has been developed based on three key theories, namely, sustainable development theory, SNA and social sustainability theory. Sustainable development theory forms the rational basis of the framework to meet the needs of the people, which is then expanded to define the people of sustainable construction. SNA was used to operationalize the framework, followed by social sustainability theory, to establish the bases of the assessment. Each of these theories is explained briefly in the following sections.

\section{Sustainable development theory}

Sustainable development is defined as meeting the needs of our generation without compromising the ability of future generations to meet their own needs (Brundtland and Development, W. C. o. E. a, 1987), so the identification of the people and their social needs in the context of construction is required. Presley and Meade (2010) argued that sustainable construction refers to the building and spaces, construction process and the surrounding built environment. This interpretation of sustainable construction highlights three communities of stakeholders, namely, the user's community, who uses the building; the industry community, who deliver the building and are involved in the construction activities; and the neighbourhood community, who shares the built environment with the new project.

These communities are the most immediate stakeholders, who are directly influenced by the project. However, there are many other organizations linked indirectly to the project, such as central, state or local governments, local authorities, or Quangos. The key assumption is that the extended stakeholders' satisfactions will be met when the satisfactions of the immediate stakeholders are met, and ultimately, the target social value is achieved in the project. For example, the role of the government is to make sure that the project is developed properly for meeting the immediate stakeholders' needs, and thus, the government's satisfaction depends on the immediate stakeholders' satisfactions. In line with this view, Ma (2011) divided construction stakeholders into three simple groups: interested (includes neighbours society), involved (includes suppliers) and committed (includes investors). Therefore, this research focusses on the socialsustainability, as it relates to the immediate stakeholders. The three communities are discussed below.

Industry community. Industry community refers to people concerned with the construction activities, such as developing, designing, constructing, manufacturing and supplying. This group covers all the supply chain members, including building owners and developers, architects, project managers, engineers, construction contractors, operation and maintenance contractors, suppliers, manufacturers and demolition contractors. In the main, the interest of this group is about making money from initiating, such as a construction project.
User's community. Users are those people who use the constructed building in the operation stage. They require the building to run their business or activity. People in this group are changeable according to the business that runs within the building. Consequently, the interests, benefits and impacts of such a construction project on the social sustainability are varied, based on who runs the business or uses the project facility over the operation phase. Mostly, the interest of this group is related to the building's functionality and comfort.

\section{Neighbourhood community}

Neighbours are the people who live nearby and are affected by the project location. This group covers residential neighbours, commercial neighbours and those who use the surrounding paths and roads. These roles have distinct impact relations with the project. Other roles that may exist within the neighbourhood community, such as service providers, are represented by the service receiver, who fits in one of the defined neighbour groups.

Conceptually, social sustainability health check (SSHC) is a function of how a project performs and satisfies the needs of its stakeholders. As shown in Figure 1, the stakeholders' communities interact with construction project through certain social functions. Thus, if these social functions perform at the required levels that satisfy the stakeholders' social needs and interests, it will be considered that the target has been achieved. However, if the aggregated score does not meet the target assigned by the project developers, the performance optimisation is attained by identifying which indicator has failed, so it can be redressed to satisfy the corresponding stakeholder.

\section{Social network analysis}

As stated earlier, the multiplicity of stakeholders and the multifaceted social values are mapped using SNA. SNA is becoming an increasingly popular methodology for understanding and mapping the complex patterns of actors' interactions within a network system, which enables the identification of the stakeholders' positions and their perceived stakes in project evaluation context (Doloi, 2012). Provan et al. (2005) advocated that SNA is a valuable tool for understanding the network structure of a community. Further, they suggested it to be used to strengthen the relationship and the network of the community and to sustain the function of the community's social systems. Prell et al. (2009) used SNA to inform the stakeholder analysis in the context of the national resource management. They advocated that the stakeholder's categorization method often overlooked the importance of the stakeholders'. 


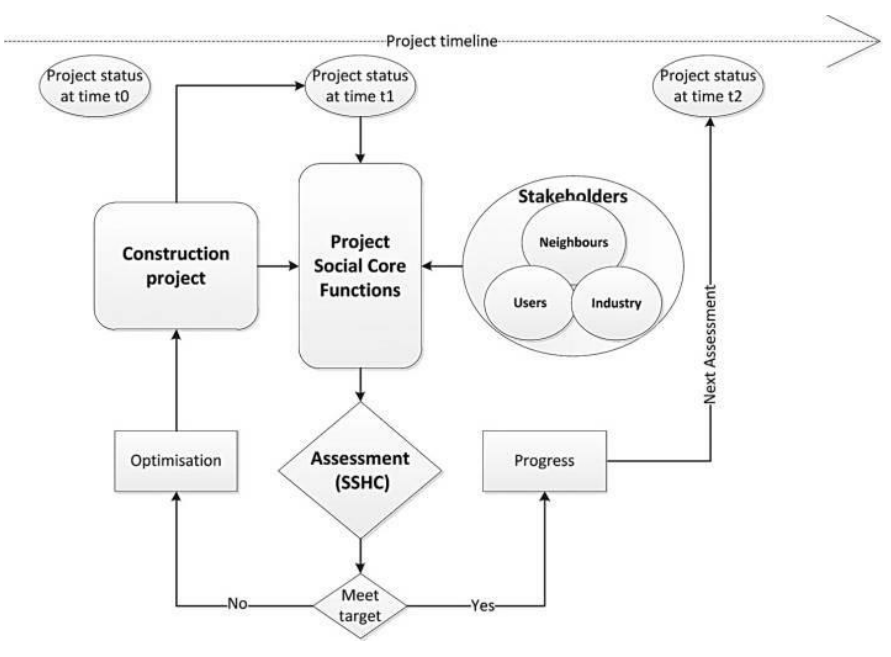

Figure 1. Assessment theoretical framework

The SNA uses functions, such as the degree of the centrality of an actor, which is the sum of the direct ties to the other actors. Strong and extensive ties to the other nodes in the network indicate that the one stakeholder is more likely to influence the others with respect to a project environment; thus, they were more important (central) in the network (Prell et al., 2009).

In the current research, the project SCFs and the stakeholders are mapped in two-mode network. In the SNA, the two-mode network allows the functions to be linked with the actors; this is unlike the one-mode network which links only the actor-toactor (Faust, 1997). The linkages between the functions and the actors are interpreted as channels for the social resources transmission. Hence, the stakeholders' perceptions of the importance of the social resources in the project can be defined as a weight of the links. These weightings represent the stakeholders' expectations and social interests associated with the core functions of the project. Therefore, the project's social importance from the different stakeholders' perspectives is integrated and defined. The identification of the stakeholders' positions within the project social network enables the evaluation of the social value received from a project. The degree of the centrality of a stakeholder represents his/her importance in the network. For this reason, the social value received is measured with respect to the stakeholders' positions in the network.

The above section identified the different communities of the construction project stakeholders. How their social interests contribute to devising the SCFs in the construction project are discussed in the following section.

\section{Social sustainability in construction project}

To integrate the concept of social sustainability within the framework discussed earlier, the concept needs to be unpacked and defined. A review of the literature shows that the social sustainability dimension is a concept in chaos (Vallance et al., 2011; Murphy, 2012). As the term social is multi-lateral, the definition of the concept is subject to the context of the definition. In its broadest sense, Harris and Goodwin (2001) stated that: a socially sustainable systemmust achieve fairness in distribution and opportunity, adequate provision of social services, including health and education, gender equity, and political accountability and participation.

Further, McKenzie (2004) defined social sustainability as a positive condition that includes equity, culture, political participation, psychological needs and a process within communities that can achieve that condition. This notion was expanded by Littig and Griessler (2005), who characterized social sustainability as being about satisfying an extended set of human needs, preserving nature and fulfilling social justice, as well as human dignity and political participation. A further redefinition was developed by Dillard and King (2008) to include four universal principles: equity, human well-being, democratic government and democratic civil society.

Bramley et al. (2009) scrutinised the social sustainability literature and found that two dimensions underlay the concept, which are social equity and sustainability of communities. Social equity is concerned with accessibility to services, and opportunities, whereas sustainability of communities is concerned with social interaction, social cohesion and social capital (Bramley et al., 2009). However, Landorf (2011) suggested that the social equity dimension has two different concepts which are equality of access to resources and opportunities, and satisfaction of the basic needs.

Social sustainability is fundamentally based on the nature of the human needs which are both physical and psychological (Landorf, 2011). The physical needs can be satisfied by providing hard infrastructure such as accessibility, shelter, water, safety and security, education and job opportunity. The psychological needs can be satisfied by providing soft infrastructure such as enabling participation, preserving culture and identity, enabling communications and social interactions and providing comfort (Hill and Bowen, 1997; McKenzie, 2004; Littig and Griessler, 2005; Chan and Lee, 2008).

However, there are different social sustainability definitions, themes and aspects, as discussed in different literature contexts (Murphy, 2012). In the context of construction projects, the concept of social sustainability is reflected through the meeting of the needs of industry, users and neighbourhood communities. Each of these communities has a unique relationship with the project and has different expectations and interests from the project. However, some social values created by a project are multi-faceted and, therefore, can benefit the three community groups. The application of the concept with respect to the three communities has been discussed below.

Industry community. The enhancement of social sustainability in this community will result in enormous repercussions, because it is considered to be the largest industrial employer worldwide with 111 million employees. In addition, the employment intensity of the construction industry is much higher in low-income countries than in the high-income countries (Wells, 2001). Thus, the development of construction projects has the capacity to enhance social sustainability and to contribute to sustainable development (Du Plessis, 2002) 
through providing welfare, health, safety and social harmony for the stakeholders of this community (Talukhaba et al., 2005). Therefore, in the UK, a number of initiatives have been established in the construction industry in response to social sustainability issues, such as the Construction Skills Certification Scheme. Macfarlane (2000) also called for innovative development and fast tracking of training programs to maximize social inclusion of local labourers in the construction industry. These initiatives provide both training and employment opportunities for construction workers.

A number of construction organizations use the Global Reporting Initiative guidelines to enhance their position by being committed to sustainability. Sustainability reporting incorporates the practice of measuring, disclosing and being accountable (to internal and external stakeholders) for the organizational performance to reach the sustainable development goal. Lamprinidi and Ringland (2008) provided a snapshot of the reporting practice in the construction industry; they identified the social themes reported, including diversity, employment, health, safety, community involvement, education and training.

Neighbourhood community. The relationship between a construction project and its surrounding environment, or its neighbourhood community, is usually addressed under topics such as urban sustainability, sustainable built environment and sustainable livelihoods. However, Chan and Lee (2008) identified the social sustainability factors of urban renewal projects through a questionnaire survey in the construction industry in Hong Kong. The study reported that "provisions facilitating daily life operations", "satisfaction of welfare requirements", "creation of harmonious living environment", "conservation of resources and the surroundings", "form of development" and "availability of open spaces" were the significant underlying factors that enhance the social sustainability of the urban environment.

In the UK, the government issued Section 106 planning agreement and the Community Infrastructure Levy to minimize the negative impact of development on local communities and to encourage the delivery of social sustainability objectives, such as job opportunities for locals and infrastructure provision. Macfarlane and Cook (2002) highlighted the importance of considering "community benefit", such as providing job opportunities and training through the regeneration scheme in their local areas; hence, contractual ways are suggested. The Considerate Constructor's Scheme was also instigated to focus on construction activities that involve being a good neighbour, as well as being clean, respectful and safe, and to provide volunteering jobs (Herd-smith and Fewings, 2008). Other activities to enhance the social sustainability of a project's neighbourhood practiced were public hearings, community engagement and knowledge transfer.

Users' community. Social is sues related to a building's users have been widely studied, especially in terms of the users' psychological and physical comfort, health and productivity (Leaman and Bordass, 2001). Over the past 30 years, the postoccupancy evaluation (POE) has been advanced, which seeks to evaluate how well the building is satisfying and meeting the occupants' requirements on health, safety, security, functionality and effeminacy, psychological comfort, aesthetic quality and satisfaction (Preiser, 2001). Moreover, most rating systemtools include social issues related to the building's users such as accessibility, comfort and space efficiency. However, Baird (2010) used the POE method to assess the performance in practice of 30 buildings that were certified as sustainable by the rating tools. Interestingly enough, however, over 60 percent of the respondents' comments were negative on such rating outcomes. Thus, it can be inferred that the current sustainability assessment tools lack consideration of social is sues that were unable to reflect the perception of users across multiple levels.

This paper, thus, presents an alternative categorization of the social sustainability functions of construction projects that were derived from empirical testing of identified social sustainability issues from a wide literature review on the concept and its related policies. As stated earlier, the identification and the factorization of the sustainability attribute and the key factors are not the key focus in other papers. However, the seven social sustainability factors (named as SCFs) are shown in Table I and discussed below. The first factor, capital performance (F1), is concerned with the socio-economic contribution of the project to the three communities (discussed above). Building a construction project stimulates the construction market through running a large, continuous and long process from the project studies until the building is demolished. These processes include materials and equipment production, and job and investment creation. Neighbourhood community also benefits economically from building a construction project in their area. The new building produces social interactions within the neighbourhood domain; these social interactions become a means for economic benefit. Such a building adds to the economic stock and the infrastructure of neighbourhood community. The measurement bases of this factor are the number of jobs being created, the volume of investment opportunities provided, the percentage of the utilization of locally produced materials and the level of the capacity improvement of the local infrastructure.

The second factor, health and physical comfort (F2), seeks to ensure the project's compliance with the regulations and requirements of the health, safety and physical comfort of the neighbourhood and the users' communities. The noises, air pollution, glare and waste also needs to be reduced, as well as the controllability of outdoor and indoor environment, and over the Project Life Cycle (PLC). Additionally, the project should improve The last factor, operation health and safety (F7), refers to the measure of operational health and safety performance of the project in relation to the industry community during the construction and demolition phases. The factor seeks to ensure the project compliance with regulations and requirements of health and safety that enhance the social sustainability of the industry community. Specifically, this factor seeks to measure the quality and the efficiency of the information provided to the workers to perform their job safely, the implementation of safety and quality management, the communication management and complaints hearing, the enhancement of the 
professional image of workers among the society and knowledge sharing and skills developments.

In the SSHC model presented in this manuscript, the SSP is achieved by maximizing the satisfaction of these broad communities of stakeholders across all the identified social sustainability core functions (discussed above and listed in Table I). The criteria related to the core functions provide a good basis for assessing social performance in the project.

\section{The SSHC model}

A dynamic assessment model is needed because as a construction project evolves along its lifecycle, the project stakeholders also change. At times, new stakeholders, relationships, rules and interests within these communities emerge and others disappear. Thus, the assessment model utilizes SNA as a tool for mapping the stakeholders' communities and for providing a complete picture of the different interactions with project. Therefore, the social is sues, created through the interactions with the project and communities, can be addressed according to the network systemof the actors. This outcome enables the measurement of the social performance of the project with respect to the stakeholder's position.

\section{Mathematical model development}

The SSP of a project is the sum satisfactions of the social needs that stakeholders received from the project. Hence, the SSHC, at a given time, is the sum of the SSP of the stakeholders' communities but with respect to the developers' target, which can be expressed as:

\section{$\mathrm{SSHC}_{\mathrm{t}}=$ Industry SSP $(\mathrm{t})+$ Users SSP $(\mathrm{t})+$ Neighbourhood SSP $(\mathrm{t})$}

Developer target of SSP $(t)$

A community SSP, at a given time, is the sum satisfactions of the stakeholders' needs with respect to their positions within their communities and the positions of the corefunctions. This can be expressed as follows:

$$
\text { A community SSP }=\bigcup_{r=1}^{n} a^{j} \cdot b_{v}^{i} \cdot \mathrm{cv}
$$

where $\mathrm{a}$ is a relative eigenvector centrality of the stakeholder to its community, which means the relative stake of the project within the community:

$$
a=\frac{\text { Eigenvector centrality (stakeholder) }}{\backslash \text { Eigenvector centrality (community) }}
$$

Where:

$\mathrm{b}=$ assessment score of the SCFs performance with respect to the stakeholder, which measure is based on the measurement criteria shown in the Table I. The maximu m possible score is 5; $c=$ a relative eigenvector centrality of SCFs to the sum of the eigenvector centralities of SCFs that are connected to a community;

$\mathrm{r}=$ stakeholders' roles;

$\mathrm{j}=$ stakeholders' eigenvector centrality index;

$\mathrm{i}=$ criteria index; and

$\mathrm{v}=$ core function eigenvector centrality index.

The normalization of the (a) and (c) values is a standard recommended practice to improve the interpretations, as discussed by Borgatti and Everett (1997).

Figure 2 shows the overall as ses sment framework for assessing the social performance of a project over its life cycle. The maximum cumulative score in the SSHC index, when the three communities interact with the project, is 15 because the highest satisfaction index for each community is 5 in a scale of 1-5 (1 being lowest performance, 5 being highest performance, and 2 4 are the intermediate values). The SSHC assessment outputs, at a given time, are the three scores of the SSP, the planned score of the SSP (based on developer's target), the actual score of the SSP (based on the SSHC assessment) and the maximu $\mathrm{m}$ possible score (which is 15 , as stated above) in that time base. The maximum possible score was adopted because the stakeholders and their interests vary along the project life, and the project developers may not target the maximum performance. The difference between the actual and planned performance can be measured along the project lifecycle. The resultant allows for an understanding of the difference in the social performance, so that the corrective action can be taken to meeting or exceeding the target over the entire life of the project.

The social indicators that belong to each community are the measurement bases of the social performance. The social performance is the degree of fulfilment of the social indicators which is an aggregated sum derived through the use of SNA.

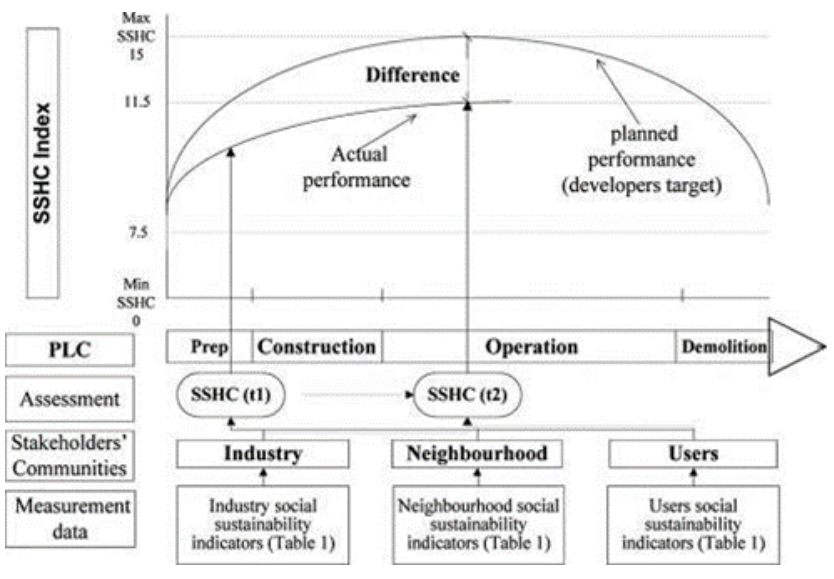

Figure 2. SSHC assessment framework

Two-mode network consists of the stakeholders roles as the first set of actors, and the social functions of the project as the second set of actors. The relation between the two sets of actors is the stakeholders' interests related to the social functions. In 
the model, the eigenvector centrality function is adopted because it allows the weighting of the stakeholders' importance with respect to the importance of social functions of the project (Borgatti and Everett, 1997). The eigenvector centrality is defined as the principal eigenvector of the adjacency matrix of a graph (Borgatti and Everett, 1997). The eigenvector score for any node is equal to:

$$
\text { Eigenvector }(x)=\frac{\mathrm{C} 1}{2 n}
$$

where $\mathrm{n}$ is the size of the vertex set as the node belongs .

\section{Application of SSHC model: a case study}

\section{Case project brief}

The Riyadh municipality, in the Kingdom of Saudi Arabia, is currently developing a project called the Economic Initiatives Project (EIP). The aim of the project is to provide a hub for any economic activities that related to societal welfare. A variety of economic activates and events are planned to run in the project, such as farmer's market, productive family market and flower market. Each day of the week will be scheduled to a selected activity, so each market will run on a weekly basis. In addition, the building project has been designed to provide a breathing space for the neighbourhood during the evening. Facilities are provided for walking, social interactions and places for social gathering and children's playgrounds.

The project has the potential to produce a huge social impact on the society; thus, it has been selected to show the model's implementation. The focus of the case study is to evaluate the social performance of the project. The project is planned to be developed in phases; the farmer's market is the first phase of the development. Based on the pilot study conducted on the farmer's market development, the implementation of the assessment model is described below.

\section{Building the interest network of the project}

To collect the data for this case study project, an ethics application was made through the University of Melbourne, and the clearance was obtained before starting the data collection process. Based on the interviews with the project authority and the project team, a number of stakeholders associated with the project were identified. Questionnaire surveys requesting the participants to identify their roles and interests in the project were disseminated. Twenty stakeholders were identified across 14 key roles in the project (as listed in Tables II and III). The stakeholders were categorised into the three key communities (e.g. neighbourhood, business and end-users), according to their roles. The fourth column in Table II highlights the roles of the stakeholders. It is worthwhile to mention that, although the roles of the typical projects have been identified and used to categorise the stakeholders in the case project, the list may vary from project to project. As noted above, the interests of the stakeholders in the project were identified through the questionnaire surveys. Using a 7-point Likert scale, the stakeholders were asked to assign the importance level of the project's SCFs in terms of their social sustainability. The perceptions of the stakeholders on the importance level of the social values are considered to be their stakes in the project. This assumption is consistent with social sustainability principles, such as meeting stakeholders' expectations and enabling stakeholders' participation. The data were then analyzed using NetMiner to generate the appropriate network maps and the relevant outputs (Pryke, 2012). Figure 3 shows the mapping of the stakeholders' interests of the project's SCFs. The concept of the eigenvector centrality was used to quantify the importance of the stakeholders and SCFs. As stated earlier, eigenvector centrality indicates the importance of the actors in the network. The higher the eigenvector centrality, the more important the stakeholder and the SCFs are in the network. Then the relative stake (a value) of each stakeholder is then determined using equation (3).

Table 2: Stakeholders identified in EIP building project.

\begin{tabular}{|c|c|c|c|}
\hline ID & Name & Stakeholder & Role \\
\hline 1 & Participant 1 & Rijadh municipality & R1 \\
\hline 2 & Participant2 & The Ministry of SocialAffairs & R2 \\
\hline 3 & Participant3 & The Ministry ofAgriculture & R2 \\
\hline 4 & Participant4 & Governmentinspector & $R 7$ \\
\hline$j$ & Participant 5 & Farmer & $R \theta$ \\
\hline 0 & rarucipant v & vom wercial paruer & ny \\
\hline 7 & Participant 7 & Dealer & $R 8$ \\
\hline 8 & Participant 8 & Customer & $\mathrm{R} 10$ \\
\hline 9 & Participant 9 & Visitor & R11 \\
\hline 10 & Participant 10 & Evening time end'user & R11 \\
\hline 11 & Participant 11 & Designer & $R j$ \\
\hline 12 & Participant 12 & Construction contracto! & RA \\
\hline 13 & Participant 13 & Supplier & $R 6$ \\
\hline 14 & Participant 14 & Maintenance contractor & RA \\
\hline 15 & Participant 15 & Building supervisor & $R j$ \\
\hline 16 & Participant 16 & Construction Iaboun & $R 3$ \\
\hline 17 & Participant 17 & Facility manager & $R j$ \\
\hline 18 & Participant 18 & Residential neighbour & $\mathrm{R} 12$ \\
\hline 19 & Participant 19 & Commercial neighbouth & $\mathrm{R} 13$ \\
\hline 20 & Participant 20 & Paths and roads user & R14 \\
\hline
\end{tabular}

Table 3: Roles of stakeholders in EIP building project

\begin{tabular}{|c|c|c|}
\hline Role & Definition & Community \\
\hline RI & Projectornaer & Industry \\
\hline R2 & Strategic partne! & \\
\hline R3 & Wouler! & \\
\hline Rt & Contractor! & \\
\hline$R j$ & Protessional & \\
\hline$R G$ & Supplier! & \\
\hline $\mathrm{RT}$ & Governmentinspector & Users \\
\hline R8 & Dealer & \\
\hline $\mathrm{R} 9$ & Selle! & \\
\hline R10 & Customer! & \\
\hline R11 & Visito! & \\
\hline R12 & Residential & Neighbourhboed \\
\hline R13 & Commercial & \\
\hline R14 & Path and road users & \\
\hline
\end{tabular}




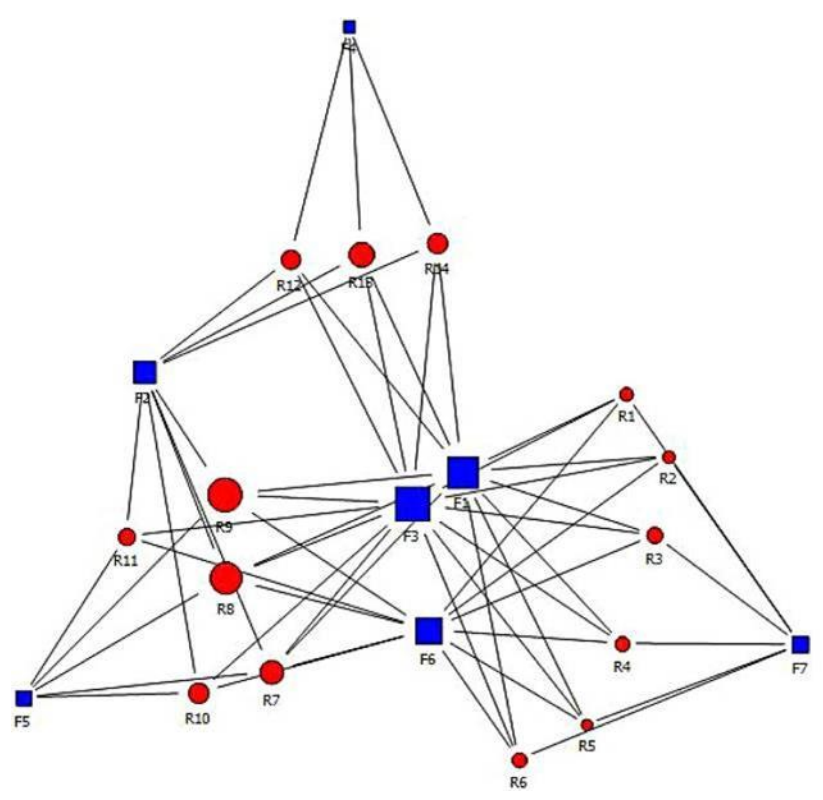

Figure 3: Social network of the EIP building project.

After the identification of the stakeholder interest network, the researchers assessed the SFCs of the project through a standardized checklist and criteria (summarized in Table I), with values from 0 to 5 , where 0 denotes "no social production", and 5 denotes "outstanding social performance" to determine the (b value) that is needed in equation (2). Appendix depicts the excerpt of the checklist with the two core functions F2 and F3 in relation to the neighbourhood community during the operation phase. The evaluation method is similar to the POE evaluation method that includes site visits, interviews and observation of the users (Preiser, 2001). The result of this evaluation process is shown in Table IV (Column 4). It is worthwhile to note that the researcher is an accredited consultant for German Sustainable Building Council and, thus, able to make a clear observation during the assessment process (DGNB, 2010).

Table IV (Column 2) shows the importance of the stakeholders in terms of eigenvector centrality. As observed in this column, and from Figure 3, the users' community were found to have the most social interests in the project. This seems to be true because they have a direct interest in the project, and the project was developed for them in the first place. The neighbourhood community came second, as it can be observed from the Table IV and Figure 3. These are consistent with project objectives which are encouraging economic activities related to social welfare, these activities run by users' community. The second objective related to providing breathing place for the neighbourhood community. Importantly, when more nodes connect with a social function, they receive a higher eigenvector. Hence, the relative stake, as seen in the Table IV (Column 3), has been adopted to balance the different communities. The SSP of the stakeholders' communities shown in the Table IV (Column 5) was derived from the as sessment of their satisfaction level and their interest position within the project social functions, using equation (2). Table V highlights the importance level of the SCFs of the project in relation to the project stakeholders, in descending order. The ranking of the SCFs was influenced by the number of communities benefitting from that social function. Such information allows the developers to identify which enhancement of the project social functions would improve the project social performance better.

Table 4: Eigenvector centrality and social sustainability performance of EIP building project

\begin{tabular}{|c|c|c|c|c|c|}
\hline ID & $\begin{array}{l}\text { Stakeholder } \\
\text { eigenvector } \\
\text { centrality }\end{array}$ & $\begin{array}{l}\text { Relative stake } \\
\text { (equation [3]) }\end{array}$ & $\begin{array}{l}\text { Social performance } \\
\text { according to } \\
\text { (Table } \mathrm{I} \text { ) (b value in } \\
\text { the equation [2]) }\end{array}$ & $\begin{array}{c}\text { SSP } \\
\text { (equation [2]) }\end{array}$ & $\begin{array}{l}\text { Weighted } \\
\text { SSP }(\%\end{array}$ \\
\hline$\overline{\mathrm{R} 1}$ & 0.241 & 0.170 & 4.1 & 3.57 & 71.4 \\
\hline $\begin{array}{l}\mathrm{R} 2 \\
\Omega \mathrm{J}\end{array}$ & $\begin{array}{l}0.225 \\
v . \angle 40\end{array}$ & $\begin{array}{l}0.159 \\
U .1 / 4\end{array}$ & 4.4 & & \\
\hline $\begin{array}{l}\text { R4 } \\
\text { R5 } \\
\text { R6 }\end{array}$ & $\begin{array}{l}0.236 \\
0.213 \\
0.254\end{array}$ & $\begin{array}{l}0.167 \\
0.151 \\
0.179\end{array}$ & $\begin{array}{l}3.6 \\
2.4 \\
3.9\end{array}$ & & \\
\hline R7 & 0.297 & 0.198 & 3.9 & 4.04 & 80.8 \\
\hline R8 & 0.343 & 0.228 & 4.4 & & \\
\hline R9 & 0.355 & 0.236 & 3.8 & & \\
\hline R10 & 0.263 & 0.175 & 3.8 & & \\
\hline R11 & 0.244 & 0.163 & 4.3 & & \\
\hline R12 & 0.249 & 0.318 & 4.4 & 4.30 & 86.0 \\
\hline R13 & 0.282 & 0.361 & 4.6 & & \\
\hline R14 & 0.251 & 0.321 & 3.9 & & \\
\hline \multicolumn{4}{|c|}{$\mathrm{SSHC}_{\text {3сcorea }}$} & 11.91 & 79.4 \\
\hline \multicolumn{6}{|c|}{${ }^{2}$ Maximum possible score of SSHC is 15} \\
\hline
\end{tabular}

Table 5: Eigenvector centrality of SSHC core functions of the EIP project

\begin{tabular}{|l|l|c|}
\hline ID & $\begin{array}{l}\text { SSHC core } \\
\text { function s }\end{array}$ & $\begin{array}{c}\text { Eigenvector } \\
\text { centrality }\end{array}$ \\
\hline F3 & Accessibility & 0.552 \\
\hline F1 & $\begin{array}{l}\text { Capital } \\
\text { perform ance }\end{array}$ & 0.505 \\
\hline F6 & $\begin{array}{l}\text { Psychological } \\
\text { comfort }\end{array}$ & 0.426 \\
\hline F2 & $\begin{array}{l}\text { Healt and } \\
\text { physical } \\
\text { comfort }\end{array}$ & 0.367 \\
\hline F5 & Usability & 0.249 \\
\hline F7 & $\begin{array}{l}\text { Operation } \\
\text { health and } \\
\text { safety }\end{array}$ & 0.209 \\
\hline F4 & Integration & 0.138 \\
\hline
\end{tabular}

\section{Analysis of SSHC result of the EIP building project}

As seen in Table IV, the assessment of the SSP of the project, using the SSHC tool, resulted in a score of 79.4 per cent, at a specified time (i.e. now) of the project life. Although the measurement methods require a particular outcome across every core function to achieve the idealized outcomes in projects (e.g. 100 per cent performance), this is not always possible in most projects. Thus, the use of checklist allows a precise determination of the realistic performance within a score of $0-100$ per cent (where 0 per cent denotes no performance, and 100 per cent denotes highest performance).

In this project, the developers sought to achieve the best score possible, so the evaluated score was not satisfactory. Indeed, the social performance of the project, in relation to users and neighbourhood communities, was 80.8 and 86.0 per cent, respectively; these results were higher than the overall score. The social performance of the project in relation to the industry community was 71.4 per cent, which explains the shortage in 
the social performance. This underperformance, in relation to the industry's stakeholders, was because of several project's social functions issues. The capital performance (F1) of the project functions did not provide enough job opportunities for locals, and some of the building materials used in the project were not locally produced. Two other underperforming SCFs, related to the industry community, were accessibility (F3) and operation health and safety (F7). As the project has been partially operated, the accessibility to the project by construction labourers and contractors was not easy. Moreover, the contractor did not comply with the operation health and safety requirements because of two main issues: the interruption of the project operation and the lack of operation health and safety regulations in Saudi Arabia. Almahmoud et al. (2012) investigated the safety practice in Saudi Arabian construction industry and found it far from mature.

The project's SCFs, in relation to the users' community, are mostly performing satisfactorily. However, the failures in the performance came from the usability (F5) and psychological comfort (F6) core functions. The project was being used before being completely handed over, and thus, the safety information provided to the users was not sufficient. In addition, most sellers in the project complained about the territoriality of their spots which were not clearly defined. The project's SCFs, in relation to the neighbourhood's community, achieved mostly a satisfactory performance. However, the failures in the performance came from the lack of integration (F4); there was no knowledge sharing or training being provided for the neighbourhood. In addition, there was a lack of proactive engagement with the neighbourhood in terms of the building design and the planning of the construction process.

Further, the application of the SSHC tool resulted in ranking the SCFs of the project. The accessibility (F3) and the capital performance (F1) functions were ranked the most important social factors in the project in terms of the eigenvector centrality. The three stakeholder communities were connected with these social functions. Consequently, an enhancement of these factors leads to a higher enhancement of the social performance of the project. The second important SCFs were psychological comfort (F6) and health and physical comfort (F2), as they were connected to two communities. The third SCFs were connected to one community, namely, usability (F5), operation health and safety (F7) and integration (F4). Although these core functions came last, they should not be marginalized in their importance because they have a direct influence on a specific community.

\section{Discussions and findings}

The research has resulted in an assessment framework for the evaluation of construction project's contributions to social sustainability. The application of the model in a real-life case revealed the model capability to integrate the various stakeholders and their diverse social interests in the project. The result of the application clearly highlighted the areas of underperformance and provides a basis for enhancements. The ranking of the project's SCFs and the stakeholders' positioning in the social network within the project can assist the decision- makers to choose the best invest strategies and achieving optimal social performance in projects.

As every stakeholder presents quite differing interests and satisfactions in any project, the use of SNA adequately facilitates management of such conflicts with a converging outcome in the model. The mapping of the stakeholders with respect to their interested project's social functions in the SNA model results in numerous measures depicting the accurate stakes of respective communities within the project. This provided a holistic view of the interactions and meaningful insights into the complex relations within the construction projects. In the case study, one of the key SNA measures, the eigenvector centrality of the stakeholders, were normalized to give the three communities equal importance (Faust, 1997). However, the assessment model has the flexibility to be modified if the project developers have different views in relation to a particular project.

\section{Conclusion}

This paper presents a framework for social performance assessment in the context of the social sustainability of construction projects. Construction projects create interactions between stakeholders, which produce social is sues that need to be developed under sustainability principles, es pecially because such projects tend to have a relatively long lifecycle. The stakeholders and their interactions and interests can also vary widely from one lifecycle phase to the next. Thus, an assessment of the social performance with an appropriate functionality with a whole life cycle view is quite a challenging task. The SSHC model developed in this research attempts to advance the consideration of the social dimension and provides the means by which to consider and account for the diverse stakeholders' interests in the sustainable development of construction projects.

The key contribution of this research is the provision of framework that links the diverse social factors and stakeholders' communities of construction in a network system; hence, it allows for quantifying the social performance of the project in a systemic manner. Seven SCFs of construction project and their evaluation criteria were developed and linked to the stakeholders' communities. The model accounts for most stakeholders who interact with the construction project over its life. SNA is one of the core functionalities in the assessment model which allowed the identification of the complex network of social is sues and stakeholders of the construction project.

The application of the model was demonstrated in a single case for the purpose to test the usability and applicability of the model. However, future research may incorporate longitudinal case study to empirically test the model capability for social performance enhancement over the time.

\section{References}

- Allam, A. (2011), "Saudi construction monopoly alleged", Financial Times.

- Almahmoud, E.S., Doloi, H.K. and Panuwatwanich, K. (2012), "Linking project health to project performance indicators: multiple case studies of construction projects in 
Saudi Arabia", International Journal of Project Management, Vol. 30 No. 3, pp. 296-307. Crossref

- Baird, G. (2010), Sustainable Buildings in Practice: What the Users Think, Taylor \& Francis, Oxon. Crossref

- Bentivegna, V. (1997), in Brandon, P., Lombardi, P.L. and Bentivegna, V. (Eds), Limitations in Environmental Evaluation. Evaluation of the Built Environment for Sustainability, Spon, pp. 25-38.

- Borgatti, S.P. and Everett, M.G. (1997), "Network analysis of 2-mode data", Social Networks, Vol. 19 No. 3, pp. 243 269. $\underline{\text { Crossref }}$

- Bramley, G., Dempsey, N., Power, S., Brown, C. and Watkins, D. (2009), "Social sustainability and urban form: evidence from five British cities", Environment and Planning A, Vol. 41 No. 9, pp. 2125-2142. Crossref

- Brundtland, G.H. and Development, W. C. o. E. a. (1987), Our Common Future, Oxford University Press, Oxford.

- Burdge, R.J. (1987), "The social impact assessment model and the planning process", Environmental Impact Assessment Review, Vol. 7 No. 2, pp. 141-150. Crossref

- Chappells, H. and Shove, E. (2005), "Debating the future of comfort: environmental sustainability, energy consumption and the indoor environment", Building Research and Information, Vol. 33 No. 1, pp. 32-40. Crossref

- Chan, E. and Lee, G.K.L. (2008), "Critical factors for improving social sustainability of urban renewal projects", Social Indicators Research, Vol. 85 No. 2, pp. 243-256. Crossref

- Clarkson, M.B.E. (1995), “A stakeholder framework for analyzing and evaluating corporate social performance", Academy of Management Review, Vol. 20 No. 1, pp. 92117. $\underline{\text { Crossref }}$

- Deutsche Gesellschaft für Nachhaltiges Bauen (DGNB). (2010), “DGNB Manual”, available at: www.dgnb.de/dgnbsystem/en/ (accessed 20 May 2013).

- Dave, S. (2011), Neighbourhood density and social sustainability in cities of developing countries, Sustainable Development, Vol. 19 No. 3, pp. 189-205 Crossref

- Dillard, J. and King, M.C. (2008), Understanding the Social Dimension of Sustainability, Routledge, New York. Crossref

- Doloi, H.K. (2012), “Ass essing stakeholders' influence on social performance of infrastructure projects", Facilities, Vol. 30 Nos 11/12, p. 6. Crossref

- Du Plessis, C. (2002), “Agenda 21 for sustainable construction in developing countries: a discussion document", CSIR Building and Construction Technology.

- Edum-Fotwe, F.T. and Price, A.D.F. (2009), “A social ontology for appraising sustainability of construction projects and developments", International Journal of Project Management, Vol. 27 No. 4, pp. 313-322. Crossref

- Elkington, J. (1998), "Partnerships from cannibals with forks: the triple bottom line of 21st-century business", Environmental Quality Management, Vol. 8 No. 1, pp. 3751. Crossref

- Faust, K. (1997), “Centrality in affiliation networks", Social Networks, Vol. 19 No. 2, pp. 157-191. Field, A. (2009),
Discovering Statistics Using SPSS, Sage Publications, Thousand Oaks, CA. Global Reporting Initiative (GRI). (2011), "G3.1 Sustainability reporting guidelines", available at:

https://www.globalreporting.org/res ourcelibrary/G3.1Guidelines-Incl-Technical-Protocol.pdf (accessed March 2014).

- Gibson, R.B. (2006), "Sustainability assessment: basic components of a practical approach", Impact Assessment \& Project Appraisal, Vol. 24 No. 3, pp. 170-182. Crossref

- Harris, J.M. and Goodwin, N.R. (2001), Volume Introduction. ASurvey of Sustainable Development, Social and Economic Dimensions, Island Press, USA, pp. 27-36.

- Herd-smith, A. and Fewings, P. (2008), "The implementation of social sustainability in regeneration projects: Myth or reality?", The Construction and Building Research Conference of the Royal Institution of Chartered Surveyors, RICS, Dublin.

- Hill, R.C. and Bowen, P.A. (1997), "Sustainable construction: principles and a framework for attainment", Construction Management and Economics, Vol. 15 No. 3, pp. 223-239. Crossref

- Hutchins, M.J. and Sutherland, J.W. (2008), “An exploration of measures of social sustainability and their application to supply chain decisions", Journal of Cleaner Production, Vol. 16 No. 15, pp. 1688-1698.

- Lamprinidi, S. and Ringland, L. (2008), "A snapshot of sustainability reporting in the construction and real estate sector", available at: www.globalreporting.org/NR/rdonlyres/ 13865428-9EAC4EB0-A8E3-A 31AA2F5C38C/3470/CRESSReport.pdf (accessed 31 July 2011).

- Landorf, C. (2011), "Evaluating social sustainability in historic urban environments", International Journal of Heritage Studies, Vol. 17 No. 5, pp. 463-477. Crossref

- Leaman, A. and Bordass, B. (2001), “Assessing building performance in use 4: the probe occupant surveys and their implications", Building Research \& Information, Vol. 29 No. 2, pp. 129-143. Crossref

- Littig, B. and Griess ler, E. (2005), "Social sustainability: a catchword between political pragmatism and social theory", International Journal of Sustainable Development, Vol. 8 No. 1, pp. 65-79. Crossref

- Liu, A.M.M., Fellows, R. and Tuuli, M.M. (2011), “The role of corporate citizenship values in promoting corporate social performance: towards a conceptual model and a research agenda", Construction Management and Economics, Vol. 29 No. 2, pp. 173-183. Crossref

- Lützkendorf, T. and Lorenz, D. (2006), "Using an integrated performance approach in building assessment tools", Building Research \& Information, Vol. 34 No. 4, pp. 334-356. Crossref

- McGuire, J.B., Sundgren, A. and Schneeweis, T. (1988), "Corporate social responsibility and firm financial performance", Academy of Management Journal, Vol. 31 No. 4, pp. 854-872. Crossref 
- McKenzie, S. (2004), "Social sustainability: towards some definitions", Working Paper Series, No.27, Magill, Hawke Research Centre, University of South Australia.

- Ma, U. (2011), No Waste: Managing Sustainability in Construction, Gower, Ashgate, Burlington, VT, Farnham, Surrey.

- Macfarlane, R. (2000), Using Local Labour in Construction, The Policy Press, Bristol. Macfarlane, R. and Cook, M. (2002), Achieving Community Benefits Through Contracts: Law,

- Policy And Practice, The Policy Press, UK.

- Maignan, I. and Ferrell, O. (2004), "Corporate social responsibility and marketing: an integrative framework", Journal of the Academy of Marketing Science, Vol. 32 No. 1, pp. 3-19. Crossref

- Missimer, M., Robèrt, K.H., Broman, G. and Sverdrup, H. (2010), "Exploring the possibility of a systematic and generic approach to social sustainability", Journal of Cleaner Production, Vol. 18 Nos 10/11, pp. 1107-1112. $\underline{\text { Crossref }}$

- Murphy, K. (2012), "The social pillar of sustainable development: a literature review and framework for policy analys is", Sustainability: Science, Practice, \& Policy, Vol. 8 No. 1, pp. 15-29.

- Pearce, D. (2006), "Is the construction sector sustainable?: definitions and reflections", Building Research and Information, Vol. 34 No. 3, pp. 201-207. Crossref

- Pope, J., Annandale, D. and Morrison-Saunders, A. (2004), "Conceptualising sustainability assessment", Environmental Impact Assessment Review, Vol. 24 No. 6, pp. 595-616. $\underline{\text { Crossref }}$

- Preiser, W.F.E. (2001), “The evolution of post-occupancy evaluation: toward building performance and universal design evaluation", Federal Facilities Council Technical Report, Learning from our Buildings: A State-of-thePractice Summary of Post-occupancy Evaluation, pp. 9-22.

- Prell, C., Hubacek, K. and Reed, M. (2009), "Stakeholder analysis and social network analysis in natural resource management", Society \& Natural Resources, Vol. 22 No. 6, pp. 501-518. Crossref

- Presley, A. and Meade, L. (2010), "Benchmarking for sustainability: an application to the sustainable construction industry", Benchmarking: An International Journal, Vol. 17 No. 3, pp. 435-451. Crossref

- Provan, K.G., Veazie, M.A., Staten,L.K. and Teufel-Shone, N.I. (2005), "The use of network analysis to strengthen community partnerships", Public Administration Review, Vol. 65 No. 5, pp. 603-613. Crossref

- Pryke, S. (2012), Social Network Analys is in Construction, Wiley-Blackwell, West Sussex.

- Rogers, P.P., Jalal, K.F. and Boyd, J.A. (2008), An Introduction to Sustainable Development, Earthscan/James \& James, London.

- Talukhaba, A., Ngowi, A.B. and Letlape, K. (2005), "Implementation of socio-economic sustainability in construction projects at the planning stage in developing countries", Paper presented at the SB13 South Africa conference, Johannesburg.

- Vallance, S., Perkins, H.C. and Dixon, J.E. (2011), "What is social sustainability? A clarification of concepts", Geoforum, Vol. 42 No. 3, pp. 342-348. Crossref

- Van der Sluijs, J.P. (2002), "A way out of the credibility crisis of models used in integrated environmental assessment", Futures, Vol. 34 No. 2, pp. 133-146. Crossref

- Vanclay, F. (2004), "The triple bottom line and impact assessment: How do TBL, EIA, SIA, SEA and EMS relate to each other?", Journal of Environmental Assessment Policy \& Management, Vol. 6 No. 3, pp. 265-288. Crossref

- Waddock, S.A. and Graves, S.B. (1997), "The corporate social performance-financial performance link", Strategic Management Journal, Vol. 8 No. 4, pp. 303-319. Crossref

- Wells, J. (2001), "The construction industry in the twentyfirst century: its image, employment prospects and skill requirement", International Labour Organization, Geneva.

- Zhenhong, G., Wennersten, R. and Assefa, G. (2006), "Analysis of the most widely used building environmental assessment methods", Environmental Sciences, Vol. 3 No. 3, pp. 175-192. Crossref 